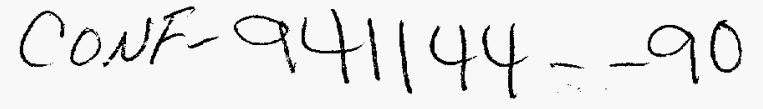

\title{
NANOINDENTATION AND NANOSCRATCHING OF HARD COATING MATERIALS FOR MAGNETIC DISKS
}

\author{
T.Y. TSUI*, G.M. PHARR*, W.C. OLIVER**, Y.W. CHUNG***, E.C. CUTIONGCO***, \\ C.S. BHATIA $\dagger$, R.L. WHITE $\dagger$, R.L. RHODES $\$$, and S.M. GORBATKIN $\$$ \\ * Department of Materials Science, Rice University, P.O. Box 1892, Houston, TX 77251 \\ ** Nano Instruments, Inc., P.O. Box 14211, Knoxville, TN 37914 \\ *** Dept. of Materials Science and Engineering, Northwestern University, Evanston, IL 60208 \\ $\dagger$ IBM Storage Systems Division, 5600 Cottle Road, San Jose, CA 95193 \\ $\S$ Oak Ridge National Laboratory, Solid State Division, P.O. Box 2008, Oak Ridge, TN 37831
}

\section{ABSTRACT}

Nanoindentation and nanoscratching experiments have been performed to assess the mechanical and tribological behavior of three thin film materials with potential application as wear resistant coatings for magnetic disk storage: (1) hydrogenated-carbon (CHx); (2) nitrogenated-carbon ( $\mathrm{CNx}$ ); and (3) boron suboxide (BOx). The hardness and elastic modulus were measured using nanoindentation. Ultra-low load nanoscratching tests were performed to assess the relative scratch resistance of the films and measure their friction coefficients. The mechanical and tribological performance of the three materials are discussed and compared.

\section{INTRODUCTION}

Thin overcoats are commonly applied to rigid magnetic disks to protect the underlying magnetic layers from damage resulting from head-disk contact during operation [1-3]. As storage densities increase, the role of the protective overcoat becomes increasingly important, since higher densities are achieved by reducing the height at which the head flies above the disk, thereby increasing the frequency of head-disk contact. In general, a good overcoat is a hard, wear-resistant material which can be deposited smoothly and uniformly on the magnetic film and to which a lubricant can be bonded to reduce friction in the head-disk interface.

To date, most overcoats have been based on various forms of sputter-deposited, hydrogenated-carbon. Recently, however, new processing technologies have allowed for the production of smooth, thin films of other materials, which, because of their extreme hardness, may be important new candidates for overcoat protection [4-6]. Here, an initial investigation of the mechanical properties of two of these materials - nitrogenated-carbon and boron suboxide are reported. The properties measured using nanoindentation and nanoscratching techniques are compared with those of a conventional hydrogenated-carbon film.

\section{PROCEDURE}

The materials examined in this study were prepared at three different laboratories using silicon as a substrate. The hydrogenated-carbon film $(\mathrm{CHx})$ was made at the IBM Storage Systems Division, San Jose, CA. The film was sputter-deposited from a carbon source onto a stationary silicon substrate in a $\mathrm{H}_{2} / \mathrm{Ar}$ mixture at a base pressure of $10^{-7}$ Torr. The sputter pressure was 5-10 mTorr, and the sputter power was adjusted to achieve a deposition rate of $0.5 \mathrm{~nm} / \mathrm{sec}$. The resulting $300 \mathrm{~nm}$ thick film was amorphous and contained a hydrogen concentration of about 20 atomic \%.

The nitrogenated-carbon film $(\mathrm{CNx})$ was produced at Northwestern University using DC magnetron sputtering in a $\mathrm{N}_{2} / \mathrm{Ar}$ atmosphere. A nitrogen partial pressure of $0.2 \mathrm{mTorr}$ and a total gas pressure of $4 \mathrm{mTorr}\left(\mathrm{Ar}+\mathrm{N}_{2}\right)$ were employed with a pulsed DC substrate bias of -250 $V$. The film was deposited at an average deposition rate of $0.17 \mathrm{~nm} / \mathrm{s}$ to a total thickness of

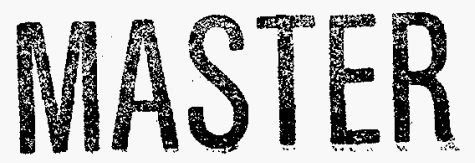

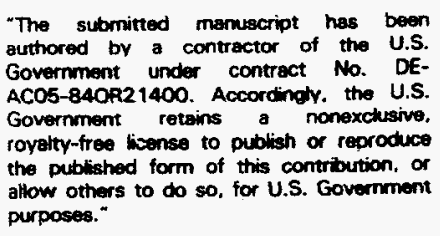

authored by a contractor of the U.S. Government under contract No. DE-

Government retsins a nonaxchusive. rovalty-free license to publish or reproduce allow others to do so, for U.S. Government purposes." 

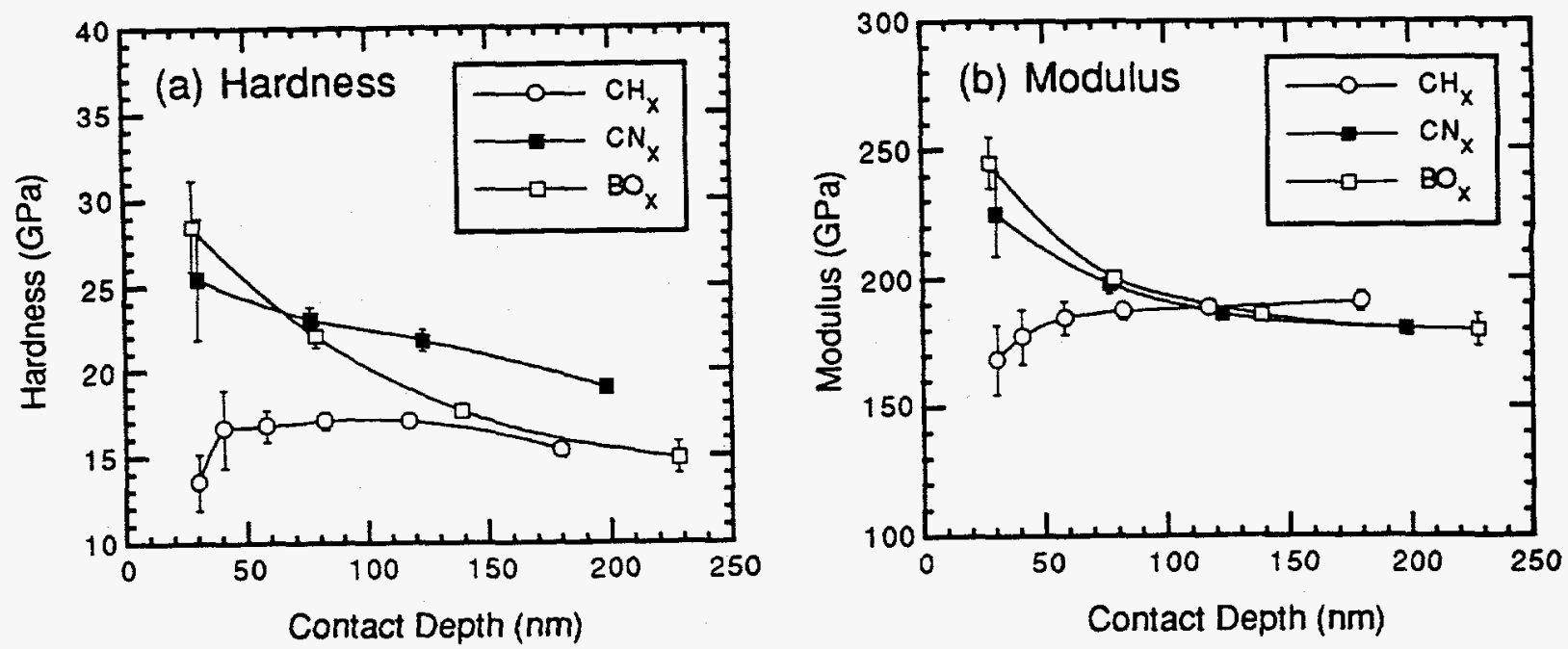

Figure 1. Nanoindentation measurements of (a) hardness and (b) elastic modulus.

$608 \mathrm{~nm}$. The film was predominantly amorphous and contained a nitrogen concentration in the range $23-28$ atomic \%.

An electron cyclotron resonance (ECR) microwave plasma system at the Oak Ridge National Laboratory was used produce the boron suboxide film (BOx). A high temperature effusion cell injected boron into an $\mathrm{Ar} / \mathrm{O}_{2} \mathrm{ECR}$ plasma for deposition of the boron suboxide onto a silicon substrate maintained at temperatures in the $75-300^{\circ} \mathrm{C}$ range. The film was deposited at a microwave power of $1000 \mathrm{~W}$, an oxygen partial pressure of $0.7 \%$, a total gas pressure of $0.55 \mathrm{mTorr}$, and no rf bias. The $210 \mathrm{~nm}$ thick film contained 11 atomic $\%$ oxygen as determined by RBS methods. Details of the system and processing conditions are given elsewhere [6].

The mechanical behavior of the films was investigated using nanoindentation and nanoscratching techniques. Nanoindentation tests were conducted using a sharp Berkovich diamond to measure the hardness, $\mathrm{H}$, and elastic modulus, $\mathrm{E}$, of the films using the method developed by Oliver and Pharr [7]. Nanoscratching experiments were performed using a system described elsewhere [8] to qualitatively assess the relative resistance of the materials to scratching and to measure friction coefficients. The scratch experiments were performed with a Berkovich diamond oriented in a face-forward direction, i.e., with a face of the diamond, rather than an edge, in the direction of scratching. The diamond was not as sharp as those used in the nanoindentation testing, having been blunted by previous scratch experiments in hard ceramics.

During each scratch test, the diamond was passed three times along the same $1000 \mu \mathrm{m}$ long track at a constant velocity of $10 \mu \mathrm{m} / \mathrm{sec}$ while the normal displacements of the tip were monitored and recorded as a function of position along the track. In the first pass, hereafter referred to as the initial scan, an extremely light, constant load of $20 \mu \mathrm{N}$, which produced no damage or permanent deformation in any of the films, was applied to the diamond to map the slope and contour of the surface. The scratch was then produced in the second pass by linearly ramping the load from a minimum value of $20 \mu \mathrm{N}$ to a maximum of $100 \mathrm{mN}$ as the specimen was translated underneath. After the load-ramped scratch was produced, a third pass, called the post-scratch scan, was used to trace the surface once again and establish the damage done during the formation of the scratch.

\section{RESULTS AND DISCUSSION}

\section{Nanoindentation}

Results of the nanoindentation tests are shown in Figs. 1a\&b. Since all the films were deposited on silicon, both the hardness and the modulus show a convergence at large contact depths to values representative of the substrate (the hardness and modulus of bulk silicon are 


\section{DISCLAIMER}

Portions of this document may be illegible in electronic image products. Images are produced from the best available original document. 
Table I. Summary of nanoindentation and nanoscratch measurements.

\begin{tabular}{lcccccc}
\hline Material & $\begin{array}{c}\text { Film } \\
\text { Thickness } \\
(\mathrm{nm})\end{array}$ & $\begin{array}{c}\text { Hardness } \\
(\mathrm{GPa})\end{array}$ & $\begin{array}{c}\text { Modulus } \\
(\mathrm{GPa})\end{array}$ & $\mathrm{H} / \mathrm{E}$ & $\begin{array}{c}\text { Critical } \\
\text { Load } \\
(\mathrm{mN})\end{array}$ & $\begin{array}{c}\text { Friction } \\
\text { Coefficient }\end{array}$ \\
\hline $\mathrm{CHx}$ & 300 & $13.6 \pm 1.6$ & $168 \pm 13$ & 0.081 & 38 & 0.13 \\
$\mathrm{CNx}$ & 600 & $25.4 \pm 3.6$ & $225 \pm 17$ & 0.113 & 59 & 0.12 \\
$\mathrm{BOx}$ & 210 & $28.5 \pm 2.7$ & $245 \pm 10$ & 0.116 & 50 & 0.13 \\
\hline
\end{tabular}

$12 \mathrm{GPa}$ and $163 \mathrm{GPa}$, respectively [9-11]). Hardness and modulus values for the films are obtained at smaller depths, for which it is seen that there is a clear difference in the properties of the three materials. For purposes of discussion, the $\mathrm{H}$ and $\mathrm{E}$ values at a contact depth of 30 $\mathrm{nm}$ will be considered as representative of the film. They are summarized in Table I.

Examination of Table I shows that the BOx and $\mathrm{CNx}$ films are considerably harder than the $\mathrm{CHx}$. With values of $28.5 \mathrm{GPa}$ for the $\mathrm{BOx}$ and $25.4 \mathrm{GPa}$ for the $\mathrm{CNx}$, the hardnesses of these materials are comparable to sapphire, and are greater than the $13.6 \mathrm{GPa}$ hardness of the hydrogenated-carbon film by a factor of about 2 . Given, then, as is generally accepted, that high hardness is an important property in overcoat films, both new materials are promising candidates.

There may also be advantages to be gleaned from these materials from their hardness-tomodulus ratios, H/E. This parameter can be used a first order measure of the materials ability to resist plastic deformation in a contact event. In very simple terms, the resistance to contact damage depends not only on the hardness of a material, but its modulus as well, since a material with a lower modulus can elastically deform to distribute the contact load over a larger area, thereby reducing the contact pressure. Contact damage is then avoided in materials with high hardness and low modulus, and the ratio of $\mathrm{H}$ to $\mathrm{E}$ can be used as a first order measure of this resistance. As a more concrete example, it is known that certain forms of glassy-carbon with extremely high $\mathrm{H} / \mathrm{E}$ ratios do not form permanent hardness impressions at all when indented with a sharp Vickers diamond; rather indentation contact is entirely elastic and the contact impression recovers fully upon unloading [12]. With this in mind, it is notable that both the boron suboxide and the nitrogenated-carbon have $\mathrm{H} / \mathrm{E}$ ratios approximately $40 \%$ larger than the hydrogenated carbon (see Table I), and may thus be expected to be more resistant to plastic contact damage.

\section{Nanoscratching}

The results of the nanoscratching tests for the three materials are summarized in Figs. 2ac. Each figure includes an optical micrograph of the scratch with arrows marking the beginning and the end of the scratch track along with a corresponding plot of the vertical displacements of the diamond during the initial scan, the load-ramped scratch, and the post-scratch scan. It should be recalled that the initial scan profiles the unscratched surface, and the post-scratch scan is used to determine the surface damage caused by the scratch. The displacements for each of the three passes have been corrected to account for the slope and topography of the surface by subtracting from them the displacements measured in the initial scan. For this reason, the initial scan appears as a flat line. Note that negative displacements correspond to the scratch tip being pushed into the material, and positive displacements, which appear only in the postscratch scan, indicate that the surface has blistered outward or that debris has accumulated in the scratch track. Values for the apparent friction coefficients are also included in the plots. The friction coefficients listed in Table I were obtained from these plots by choosing the value just prior to film failure.

Fig. $2 \mathrm{a}$ shows the nanoscratching behavior of the $300 \mathrm{~nm}$ hydrogenated-carbon film. The scratch can be divided into three regions based on differences in the appearance of the scratch track. Starting from the left and moving to the right, the first region is defined by the first 370 

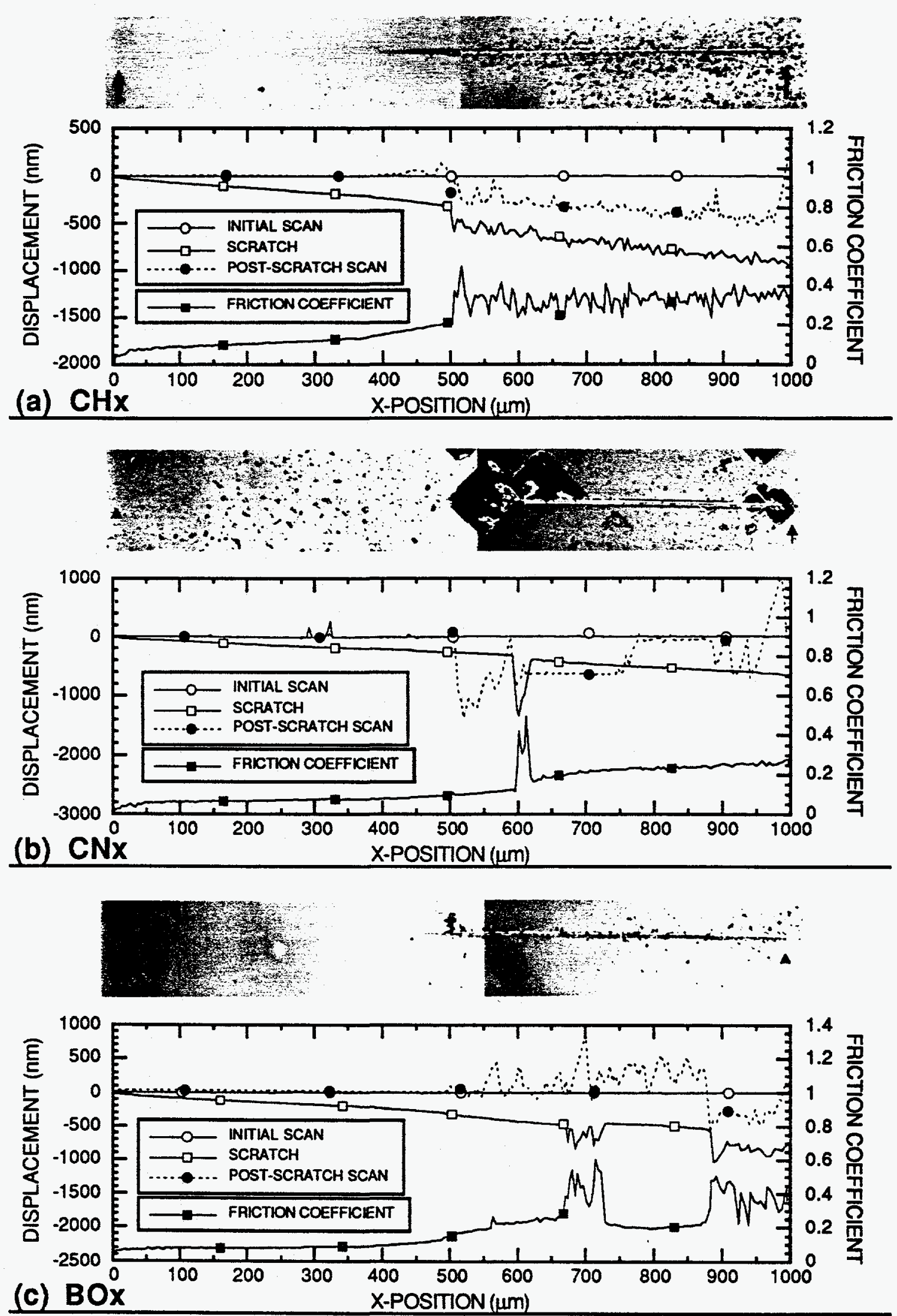

Figure 2. Optical micrographs of scratch tracks and scratch test results for: (a) hydrogenatedcarbon (CHx); (b) nitrogenated-carbon ( $\mathrm{CNx})$; and (c) boron suboxide (BOx). 
$\mu \mathrm{m}$ of the scratch. In this region, the scratch is extremely smooth and shallow, in fact, so shallow that it can be optically resolved in places only with differential interference contrast. Exactly how shallow the scratch is may also be seen by comparing the post-scratch scan to the initial scan; on the relatively gross normal displacement scale plotted in the figure, the two scans are virtually indistinguishable for the first $380 \mu \mathrm{m}$. A closer examination revealed that there is no remnant trace of the scratch in the left-hand portion of this region, corresponding to fully recovered elastic contact. Thus, scratching in the first region may be characterized as fully elastic followed by smooth elastic/plastic ploughing in which most of the normal displacement is recovered as the diamond passes by.

The second region of the hydrogenated-carbon film scratch extends from 380 to $500 \mu \mathrm{m}$. In this region, the film blisters by delamination at the film/substrate interface. The blistering may be observed in the optical micrograph and is also apparent in the post-scratch scan which shows the surface to be uplifted at numerous places in this region. Given that blistering is not acceptable in hard disk applications, the load at the beginning of this region, $38 \mathrm{mN}$, is defined as the critical load for film failure. It is also notable that there is a subtle change in the rate of increase in the coefficient of friction at the beginning of the second region (see Fig. 2a) which can be used to define the onset of delamination.

The third and final region of the scratch in the hydrogenated-carbon film begins at 500 $\mu \mathrm{m}$ and extends to the end of the scratch. It is marked by an abrupt change in the scratch displacement, as well as a substantial increase in the coefficient of friction. Examination of the optical micrograph reveals a large amount of small particle debris surrounding the scratch in this region suggesting massive brittle fragmentation of the film. The post-scratch trace shows that the depth of fragmentation at the beginning of the third region is very close to the $300 \mathrm{~nm}$ film thickness, thus indicating complete failure and removal of the film. The overall picture which emerges is that the $\mathrm{CHx}$ film remains intact and is resistant to scratch damage at loads up to $38 \mathrm{mN}$, but increasing the load further causes the film to fail, first by delamination and blistering and then by massive brittle fragmentation.

The behavior of the nitrogenated-carbon film is quite different. As shown in Fig, 2b, two distinct regions are observed in the nanoscratching behavior of this material, the first extending from $0-590 \mu \mathrm{m}$ along the scratch track. As in the $\mathrm{CHx}$ film, scratch contact in the first region is. initially elastic followed by smooth elastic/plastic ploughing with nearly fully-recoverable normal displacements. At the $590 \mu \mathrm{m}$ mark, however, corresponding to a load of $59 \mathrm{mN}$, a sudden critical event occurs, as evidenced by the large spikes in the scratch displacement and the apparent coefficient of friction. Examination of the optical micrograph shows that the critical event corresponds to the removal of a large portion of material with a very well-defined diamond shape. A closer examination revealed that the edges of the area of removed material correspond to the cleavage planes in the silicon substrate. By comparing the location of the removed material with the location of the spikes in the plots of scratch displacement and friction coefficient, it may also be concluded that the material was removed from behind the advancing scratch tip. The post-scratch surface trace shows that the removed material is not just a piece of poorly adhered film, but includes some underlying silicon as well, since the depth of the removed material is much greater than the $608 \mathrm{~nm}$ film thickness. Scratches oriented in different directions in the surface verified the tendency for the edges of the removed material to be aligned with the silicon cleavage planes. Collectively, these observations suggest that failure in this specimen occurs not by brittle fragmentation of the film, but by lateral cracking in the substrate. Apparently, the nitrogenated carbon film is well-bonded to the silicon and is much more resistant to brittle fragmentation than the hydrogenated-carbon film.

Like that of the hydrogenated-carbon, the boron suboxide scratch track can be divided into three regions, as defined by the plots and photomicrograph in Fig. $2 \mathrm{c}$. For the first $500 \mu \mathrm{m}$, scratch deformation is largely-recoverable elastic-plastic ploughing, just as in the other two materials. Film failure begins at the $500 \mu \mathrm{m}$ mark and a critical load of $50 \mathrm{mN}$. In the second region, which extends from 500 to $870 \mu \mathrm{m}$, the film remains in place on the substrate, but is cracked and blistered in a narrow band centered about the scratch track. Removal of the film by brittle fragmentation occurs in the third region, extending from $870 \mu \mathrm{m}$ to the end of the track. The depth to which material is removed, approximately $400 \mu \mathrm{m}$, is considerably greater than the $210 \mu \mathrm{m}$ thickness of the film, suggesting that some silicon is removed in addition to the 
film. It is notable that failure of this material is much "cleaner" than the other two materials in that the amount of debris surrounding the scratch track is not nearly as great.

To compare the relative scratch performance of the three materials, it is tempting to use the critical loads summarized in Table I as a distinguishing parameter. If this is done, then both the nitrogenated-carbon and the boron suboxide would appear as promising materials, since their critical failure loads are substantially higher than the hydrogenated-carbon. Such a comparison is not entirely valid, however, since the thicknesses of the three films are different, and it is well known that the critical load may vary with film thickness [13].

From a more qualitative standpoint, what can be said with some surety is that the scratch resistance of the two new materials is at least as good as that of the hydrogenated-carbon film, and unlike the $\mathrm{CHx}$ film, neither exhibits a strong tendency toward brittle fragmentation. These observations, in conjunction with the improved hardnesses and hardness to modulus ratios measured in the nanoindentation tests, suggest that both the nitrogenated-carbon and the boron suboxide merit further consideration as possible protective overcoats for magnetic hard disks.

\section{ACKNOWLEDGMENTS}

This research was sponsored by the Advanced Research Projects Agency as a part of the National Storage Industry Consortium program in Ultra High Density Recording, by the Division of Materials Sciences, U.S. Department of Energy, under contract DE-AC05840R21400 with Martin Marietta Energy Systems, Inc., and by the Texas Advanced Research Program (Advanced Technology Program) under Grant No. 003604-024.

\section{REFERENCES}

1. S. Chandrasekar and Bharat Bhushan, J. Tribology 112, 1 (1990).

2. S. Chandrasekar and Bharat Bhushan, J. Tribology 113, 313 (1991).

3. H. Ishihara, H. Yamagami, T. Sumiya, M. Okudera, A. Inada, A. Terada, and T. Nakamura, Wear 172, 65 (1994).

4. M.Y. Chen, X. Lin, V.P. Dravid, Y.W. Chung, M.S. Wong, and W.D. Sproul, Trib. Trans. 36, 491 (1993).

5. D. Li, X. Lin, V.P. Dravid, Y.W. Chung, M.Y. Chen, M.S. Wong, and W.D. Sproul, Diamond Films and Technology 4, 99 (1994).

6. S. M. Gorbatkin, R. L. Rhodes, T. Y. Tsui, and W. C. Oliver, Appl. Phys. Lett. 65 (21), 1 (1994).

7. W.C. Oliver and G.M. Pharr, J. Mater. Res. 7, 1564 (1992).

8. S.D. McAdams, T.Y. Tsui, W.C. Oliver, and G.M. Pharr, submitted to Thin Films: Stresses and Mechanical Properties V (Proceedings of the 1994 MRS Fall Meeting).

9. G. M. Pharr, W. C. Oliver, and D. R. Clarke, J. Elec. Mater, 19, 881 (1990).

10. S. Danyluk, D. S. Kim, and J Kalejs, J. Mater. Sci. Lett. 4, 1135 (1985).

11. G. Simmons and H. Wang, Single Crystal Elastic Constants and Calculated Aggregate Properties: A Handbook, 2nd Ed. (MIT Press, Cambridge, MA, 1971).

12. M. Sakai, H. Hanyu, and M. Iragaki, J. Am. Ceram. Soc., in press.

13. P.A. Steinmann, Y.Tardy, and H.E. Hintermann, Thin. Sol. Films 154, 333 (1987).

\section{DISCLAIMER}

\footnotetext{
This report was prepared as an account of work sponsored by an agency of the United States Government. Neither the United States Government nor any agency thereof, nor any of their employees, makes any warranty, express or implied, or assumes any legal liability or responsibility for the accuracy, completeness, or usefulness of any information, apparatus, product, or process disclosed, or represents that its use would not infringe privately owned rights. Reference herein to any specific commercial product, process, or service by trade name, trademark, manufacturer, or otherwise does not necessarily constitute or imply its endorsement, recommendation, or favoring by the United States Government or any agency thereof. The views and opinions of authors expressed herein do not necessarily state or reflect those of the United States Government or any agency thereof.
} 